\title{
Sialic acids in human health and disease
}

\author{
Ajit Varki \\ Glycobiology Research and Training Center, Departments of Medicine and Cellular \& Molecular \\ Medicine, University of California at San Diego, La Jolla, CA 92093-0687, USA
}

\begin{abstract}
The surfaces of all vertebrate cells are decorated with a dense and complex array of sugar chains, which are mostly attached to proteins and lipids. Most soluble secreted proteins are also similarly decorated with such glycans. Sialic acids are a diverse family of sugar units with a nine-carbon backbone that are typically found attached to the outermost ends of these chains. Given their location and ubiquitous distribution, sialic acids can mediate or modulate a wide variety of physiological and pathological processes. This review considers some examples of their established and newly emerging roles in aspects of human physiology and disease.
\end{abstract}

\section{Introduction to the biology of glycans}

Teaching of molecular and cellular biology in the standard medical curriculum still focuses on Crick's 1970 'central dogma' of molecular biology that 'DNA makes RNA makes protein' [1], along with descriptions of cells, membranes and tissues. This gives physicians the impression that nucleic acids, proteins, lipids and small molecules are the only major constituents of the human cell. In fact, another major class of macromolecules was inadequately considered during the molecular biology revolution of the last few decades, namely, sugar chains or glycans [2]. The reasons for this omission were largely technical, as glycans were more complex and difficult to study. In recent years glycans have emerged from this historical obscurity, generating a specialized field of 'glycobiology' [3] - which essentially refers to the molecular and cellular biology and physiology of glycans [4,5]. Meanwhile, preclinical textbooks still say little about glycans, and the current generation of medical students and physician-scientists are trained without adequate attention to this class of molecules. In fact, glycans are ubiquitous in all biological systems. Being particularly prominent on cell surface and secreted molecules, they are also important contributors to many physiological and pathological interactions.

This review focuses on one class of sugars called the sialic acids, which are typically found at the outermost end of glycan chains of all cell types [6-8]. These acidic sugars with a ninecarbon backbone decorate all cell surfaces and most secreted proteins of vertebrates and 'higher' invertebrates, mediating or modulating a variety of normal and pathological processes (Figure 1). First, by virtue of their negative charge and hydrophilicity, sialic acids have many structural and modulatory roles. In a second category of functions, sialic acids serve as components of binding sites for various pathogens and toxins $[6,7,9,10]$, such as those listed in Table 1. In most such interactions, a pathogen-binding protein recognizes certain forms of

Corresponding author: Varki, A. (a1varki@ucsd.edu).

Publisher's Disclaimer: This is a PDF file of an unedited manuscript that has been accepted for publication. As a service to our customers we are providing this early version of the manuscript. The manuscript will undergo copyediting, typesetting, and review of the resulting proof before it is published in its final citable form. Please note that during the production process errors may be discovered which could affect the content, and all legal disclaimers that apply to the journal pertain. 
sialic acids presented in specific linkages to a defined underlying sugar chain. Although this recognition is detrimental to the host expressing the cognate sialic acids, these molecules have nevertheless persisted on all cell types in all vertebrates for a long evolutionary time. Thus, they must have a third set of functions intrinsic to these organisms. Recent evidence indicates that this is indeed the case, with several sialic acid binding proteins having been discovered over the last few decades [6-10]. A final class of functions is 'molecular mimicry', in which successful microbial pathogens decorate themselves with sialic acids, assisting in evasion of host immunity [11] (see Table 2 for some examples). These varied functions of sialic acids are to some extent antagonistic, generating an evolutionary arms race in which vertebrate hosts need to maintain sialic acids for critical endogenous functions - even while constantly changing them to avoid rapidly evolving pathogens that are either binding to or mimicking them. Available data are consistent with this evolutionary scenario [12].

With this overview, we can now consider examples in which sialic acids mediate specific roles in health and disease. Given the likely readership, these examples are presented in an order typical of the medical curriculum. Consideration of each example is, of necessity, brief and somewhat superficial, and the emphasis is placed on areas where there have been recent advances.

\section{Anatomy and physiology}

Given their negative charge and hydrophilicity, sialic acids contribute to the biophysical features of several biological systems. For example, the negative charge on human erythrocytes and other cell types provides charge repulsion, preventing unwanted interactions of cells in the blood circulation. The density of sialic acids in the glomerular basement membrane and on the foot-processes of podocytes appears critical in maintaining the normal filtering function of the organ [13,14], and extended polysialic acid chains can affect neuronal plasticity [15-18]. The luminal surface of the vascular endothelium is also very heavily sialylated [19]. At the level of molecular physiology, sialic acids can modulate the half-life of some proteins in the circulation [20,21], especially under pathological conditions such as infections with sialidaseexpressing bacteria (see below).

\section{Pharmacology}

As mentioned above, sialic acids are critical factors determining the half-life of glycoproteins in circulation. Thus, if sialic acids are missing, underlying monosaccharides such as galactose are recognized by receptors in the liver and other organs, and the glycoprotein is rapidly cleared away [21]. It is currently unclear if this mechanism contributes towards modulating the intrinsic half-life of glycoproteins. Regardless, the phenomenon is of practical relevance because many biotherapeutic products (antibodies, cytokines and hormones) are glycoproteins [22]. Many such products must be produced in mammalian cell lines. The extent of sialylation (often called 'capping') of the glycans on therapeutic glycoproteins can vary depending on conditions of culture and production. Although a small amount of 'uncapping' is acceptable, any major degree of under-sialylation results in rapid clearance of the molecule. As such, most biotherapeutic products are tested for such terminal sialylation, often as a requirement of the US Food and Drug Administration. Many attempts are now being made to enhance sialylation in animal cells [23] or to even produce sialylated glycoproteins in yeast [24] or in insect cells [25].

Another potential impact of sialic acids on pharmacology arises from the fact that the nonhuman sialic acid $\mathrm{N}$-glycolylneuraminic acid (Neu5Gc) frequently contaminates glycoprotein biotherapeutic products [26-30]. This occurs for three reasons. First, the fear of human pathogen contamination causes most manufacturers to produce glycoprotein biotherapeutic products in non-human cell lines - which can attach Neu5Gc to the glycans on the product. 
Second, some of the media components used to culture cells (fetal calf serum and many socalled 'serum substitutes') contain substantial amounts of Neu5Gc, which gets metabolically incorporated into the therapeutic cells or glycoproteins [27,31]. Third, Neu5Gc-containing components of the animal-derived media components might be directly adsorbed onto cells designated for therapy. These issues are of potential significance because contrary to prior literature [32], we now know that all normal humans have varying and sometimes substantial levels of circulating antibodies directed against Neu5Gc [33-35]. The reason that prior studies [32] missed these antibodies was that the assay used would not have picked up most Neu5Gccontaining epitopes. Moreover, the biotherapeutic products first introduced into humans were cytokines, such as erythropoietin, which were given in very small quantities and had low levels of Neu5Gc to begin with [36]. By contrast, mouse myeloma cells have very high levels of Neu5Gc, and antibodies produced in them are correspondingly rich in this molecule [37-39]. The same is true of molecules secreted into the milk of transgenic goats [40].

The implications of this Neu5Gc contamination are still being investigated [41]. One possible outcome is variation in half-life of biotherapeutics or in transplant survival, depending upon the anti-Neu5Gc antibody profile of each patient. A more serious possibility is that formation of antigen-antibody complexes, which could secondarily enhance immune reactions against the polypeptide itself [42]. Additionally, patients receiving such products might enhance their own intrinsic anti-Neu5Gc antibody production. Such circulating antibodies could also be of pathological relevance, as normal humans are meanwhile consuming Neu5Gc in food and metabolically incorporating it into cell types such as endothelia and epithelia [34]. In the final analysis there remains some controversy about the significance of Neu5Gc contamination of biotherapeutic agents and cells. Regardless, in the long run it would seem sensible to find ways to avoid injecting humans with a potentially immunogenic non-human molecule.

\section{Fertilization and development}

Much evidence suggests that various glycans (including sialic acids) can influence fertilization, not only during sperm-egg contact [43] but also during interactions of sperm with various fluids and surfaces of the female reproductive tract before it reaches the ovum [44]. For example, there is an agglutinin in the endometrium that recognizes sialic acids [45], and sialic acids appear to be directly involved in fertilization in some systems [46]. However, few definitive conclusions have been reached. Sialic acids also affect embryogenesis. Despite the fact that cultured cells can survive and divide in the absence of these sugars, genetic elimination of sialic acid production in the mouse results in early embryonic lethality [47]. The mechanism of lethality is unknown.

\section{Genetics}

There are about sixty genes known to be involved in sialic acid biology [48], and the extent to which they are critical for normal development and physiology is being investigated. The embryonic lethality mentioned above was induced by experimental inactivation of $G N E$, the gene which encodes the enzyme responsible for synthesis of sialic acids. In humans, missense mutations of the same gene result in two genetic disorders of sialylation compatible with postembryonic survival. First, certain mutations of GNE are associated with hereditary inclusion body myopathy, also sometimes called distal myopathy with rimmed vacuoles [49-52]. This unusual disease and some related disorders are myopathies that appear late in life and that spare some muscle groups. There is controversy as to whether the myopathy is primarily due to (i) a lack of sialic acid production, (ii) some other as-yet-unknown function of $G N E$ or (iii) a combination of the two [53,54], as well as whether the mouse model of the disease is representative of the human disorder [53,54]. In another disease, the lack of feedback inhibition of GNE by the downstream product cytidine monophosphate (CMP)-sialic acid results in 
massive overproduction of sialic acids, which are excreted into body fluids [55-57]. Individuals with the latter disorder, called sialuria, can have varying degrees of involvement of organ systems, including the brain. Again, details of pathological mechanisms are unclear. Another genetic disorder involves a defect in transport of sialic acids from lysosomes into the cytosol. A severe form of this defect is infantile sialic acid storage disease [58,59], and the milder version is called Salla disease [60]. Finally, 'sialidoses' are defects in the sialidase that removes sialic acids from glycoconjugates, resulting in accumulation of sialic-acid-containing macromolecules in the lysosome [61].

\section{Pathology}

Changes in sialic acid expression are seen in many pathological states, several of which are discussed in later sections. These changes can be detected in histological sections by using plant lectins or antibodies to detect specific sialylated glycans [62,63]. In clinical pathology, sialic acid measurements of body fluids are used to predict disease risk. There have been many papers suggesting that measurements of total sialic acid in the serum [64-67] can predict the risk of various diseases. However, the logic by which such measurements are of prognostic value is largely unknown - one possibility is that it is a general indication of the 'acute phase response' in which hepatocytes increase their secretion or various heavily sialylated glycoproteins [68-70]. One possibility is that such glycoproteins engage inhibitory Siglecs and tune down the innate immune response [71]. There is also literature linking sialic acid levels on lipoproteins to cardiovascular disease risk, apparently by affecting the interactions of lipoproteins with endothelium [72,73]. Some sialylated molecules can be detected in the serum as markers of cancer progression (see below). Finally, loss of sialylation on serum transferrin is used as a screening test both for chronic alcohol consumption [74] and for congenital disorders of glycosylation [75-77].

\section{Microbiology and infectious disease}

Given their terminal location and wide distribution, sialic acids are not surprisingly the targets for binding by a large number of pathogenic organisms and their toxins [9]. Some examples are listed in Table 1. It can be seen that binding specificity goes beyond simple recognition of sialic acid in most cases, including the types of sialic acids, their modifications, and their linkage to the underlying sugar chain. Perhaps the best-known role of sialic acids is in binding of influenza viruses to airway epithelium, a critical first step in the process of infection of a cell by the virus [78,79]. In this regard, there has been much attention recently on avian influenza ('the bird flu') and the risk that this virus might 'jump' into humans [80]. Such 'jumps' require the hemagglutinin component of the virus to undergo specific mutations, switching from preferentially recognizing the $\alpha 2$-3-linkage of sialic acids found in the intestinal epithelium of birds (where the virus resides), to preferentially binding $\alpha 2$-6-linked sialic acids, which are enriched on the airway epithelium of humans $[78,81,82]$. In fact, such a direct transmission is rather rare. More commonly, the virus makes its way from wild birds into poultry, and then into other domesticated mammals such as the pig, which is claimed to act as a 'mixing vessel' as it has both $\alpha 2-3$ - and $\alpha 2$-6-linked sialic acids on the epithelium [78]. There is now evidence that a direct bird to human transfer did occur at least once before, when the infamous 1918 influenza pandemic killed tens of millions of people [83,84]. Recent examples of severe and even lethal human infections with avian flu might be explained by the fact that these individuals inhaled a very large dose of virus, which reached the lower airways, where $\alpha 2-3$-linked sialic acids are present in humans [80]. Fortunately, there have yet to be conclusive cases of human-to-human transmission of avian influenza. Of course, pathogen binding can also be blocked by the decoy function of soluble mucins, which are secreted into airways and carry large amounts of sialic acids [85]. This complexity [82] appears to have not been considered in many current studies that try to explain influenza pathogenesis. 
Meanwhile, many successful pathogens express sialic acids on their own surfaces (see Table 2). Control of the alternative complement pathway by recruitment of factor $\mathrm{H}$, masking of underlying epitopes, enhanced intracellular survival and reduced immunogenicity result from this sialic acid expression [86-88]. However, such processes cannot fully explain why bacteria go to elaborate lengths to not only synthesize sialic acids but also display them on extended glycan chains that almost perfectly mimic mammalian structures $[11,89]$. We have suggested that recognition of these complex sialylated glycans by CD33-related Siglecs might send a negative signal to innate immune cells, thereby enhancing survival of the bacteria $[12,89]$. Studies of this possibility are currently under way.

\section{Immunology}

Sialic acids are critical components of most ligands for the selectin family of cell adhesion molecules, which mediate leukocyte rolling along endothelium, as well as other interactions between immune cells and/or involving platelets $[8,10]$. Sialic acids are also the ligands for the Siglec family of cell adhesion molecules, which appear to be involved in regulating the immune response $[8,12,90]$. Marked changes in sialic acid linkages occur during the development of immune cells. For example, during thymic development of T cells, upregulation of the enzyme ST3Gal-I causes 'capping' of a glycan structure otherwise recognized by the lectin peanut agglutinin. This developmental change is conserved in vertebrate evolution, and genetic disruption of this transition results in a loss of cytotoxic $\mathrm{T}$ cells, apparently accelerating a normal mechanism of $\mathrm{T}$ cell turnover after an immune response [91]. Also, $\alpha 2-6-$ linked sialic acids are markedly upregulated during the development of B cells [92], coinciding with the binding preference of the B cell surface molecule CD22/Siglec-2, which modulates the B cell response to antigen stimulation [12,90]. Sialoadhesin (Siglec 1) expressed on macrophages appears to both modulate the immune response and act as a phagocytic receptor for pathogens bearing sialic acids [93]. On a more general note, activation of immune cells appears to be associated with a downregulation of cell surface sialic acids, possibly mediated by a specific sialidase. In vitro studies suggest that this loss of sialic acids might alter aspects of the immune response [94,95].

\section{Cardiovascular physiology and disease}

One function of the high concentration of sialic acids on the luminal face of the endothelium [19] is to generate ligands for recognition by L-selectin on leukocytes [96]. Conversely, Eselectin expressed on activated endothelium, and P-selectin expressed on activated endothelium or platelets can recognize sialic-acid-containing ligands on leukocytes. These selectin-mediated interactions are dependent on additional modifications of the glycans, such as fucosylation and sulfation, and mediate processes involved in inflammation, lymphocyte recirculation, blood coagulation and reperfusion injury [96,97]. Studies in genetically deficient mice show that the P- and E-selectins also play a role in the early stages of development of atherosclerosis [98]. As mentioned earlier, the sialic acids on low density lipoproteins (LDLs) appear to play a role in determining uptake of lipids by endothelium and thus potentially in the development of atherosclerosis [72,73]. Variant alleles of P- and E-selectin have even been associated with risk of cardiovascular disease [99,100].

\section{Hematology and oncology}

Sialic-acid-containing glycans on blood cells can be the target for recognition by some 'cold agglutinin' disease antibodies [101,102]. These can arise either spontaneously (in the form of chronic cold agglutinin disease) or transiently during infections with Mycoplasma pneumoniae. The later antibodies are thought to arise from anti-idiotypic reactions against primary antipathogen antibodies that mirror the sialic-acid-binding pocket of the bacterial receptor [103]. There are distinct changes in sialylation associated with malignant 
transformation (see Table 3). In some instances it has been shown that these sialic acid structures and linkages are associated with progression and poor prognosis of carcinomas $[104,105]$. In at least one case, this association can be explained by the recognition of malignant cells by selectins, causing interactions of the circulating tumor cells with platelets, leukocytes and endothelium, and thereby facilitating metastasis [106,107]. The overall general increase in sialic acid content of tumor cells might also serve to protect them from alternative pathway complement activation by recruiting plasma factor $\mathrm{H}$ to the membrane - and, conversely, tumor cells might secrete factor $\mathrm{H}$ for the same reason [108]. Secreted or proteolytically released carcinoma mucins bearing some of these unusual forms of sialylation can be detected in the bloodstream of cancer patients and are used as diagnostic and prognostic aids $[109,110]$. The sialylated forms of these mucins are resistant to clearance by liver receptors [111], which is likely to explain the association of unusual thrombotic events with mucin-producing carcinomas - called Trousseau's syndrome $[112,113]$.

Tumors accumulate the non-human sialic acid Neu5Gc even while the patient is expressing enhanced levels of antibodies directed against these Neu5Gc-containing epitopes [114]. We have hypothesized that this occurs because the resulting weak immune response is actually beneficial to the tumor cell [34], perhaps by enhancing leukocyte infiltration and angiogenesis. Possible mechanisms for Neu5Gc accumulation include enhanced macropinocytosis and hypoxia-induced upregulation of a lysosomal transporter [31,115]. The prognostic or diagnostic significance of these anti-Neu5Gc antibodies is under investigation.

An exciting recent advance has been the discovery the somatic loss of the X-linked Cosmc gene in hematopoeitic stem cells, which could explain the aberrant sialylation seen in Sian2-3GalNAco-Ser/Thr (Tn)-polyagglutinin syndrome [116]. The same defect appears to account for most, if not all, of the classic findings of overexpression of the tumor antigen sialylTn in many carcinomas [117]. In a nutshell, mutational loss of the Cosmc chaperone causes a secondary loss of the key enzyme in O-glycan elongation. This results in the formation of truncated O-glycans that can undergo direct sialylation, generating the sialyl-Tn antigen, which is extremely rare in normal tissues [62].

\section{Neuroscience and neurology}

For unknown reasons, the brain is the organ with the highest level of sialic acids in the body, much of it in the form of sialylated glycolipids (gangliosides) [118]. As mentioned earlier, one function is the formation of polysialic acid, which is well documented as playing a part in facilitating neuronal sprouting and plasticity [15-18]. Ganglioside recognition by myelinassociated glycoprotein (Siglec-4) also plays a critical role in mediating myelin stability and in inhibiting neural sprouting after injury [119]. In this regard, an exciting recent finding is that sialidase injections enhance spinal axon outgrowth in vivo [120], possibly by destroying the ganglioside ligands for Siglec-4. In addition to the brain-affecting genetic disorders of sialic acid metabolism mentioned earlier, an autosomal recessive defect in synthesis of the ganglioside GM3 causes an infantile-onset symptomatic epilepsy syndrome associated with developmental stagnation and blindness [121]. Interestingly, mice with the same genetic defect have a milder phenotype, involving enhanced insulin sensitivity [122].

Immune reactivity against sialic-acid-containing nervous system molecules can result in severe pathology. Guillian-Barré syndrome (an acute generalized peripheral neuropathy) is often triggered by intestinal infections with Camplyobacter jejuni, which synthesizes sialylated mimics of neural gangliosides on its lipooligosaccharides [123,124]. Such infections are followed in rare instances by generation of antibodies that cross-react with gangliosides on neural cells. The pathogenic role of the antibodies is well documented, as is their specificity for different types of ganglioside structures, each resulting in somewhat different neurological 
syndromes. Some bacterial neural toxins, such as those from Botulinum and Tetanus, mediate toxicity by first recognizing sialic-acid-containing gangliosides in the brain [125]. For uncertain reasons, many of the bacteria that successfully invade the nervous system tend to decorate their surfaces with sialic acids [11]. Although such 'molecular mimicry' bestows the ability to evade immune recognition (see above), it is unclear why there is a propensity for these agents to invade the brain. Animal studies showed that bovine brain ganglioside infusions could improve recovery after stroke by uncertain mechanisms, and this approach was extended into human clinical studies [126]. However, a few of the patients developed a Guillian-Barrélike syndrome [127], apparently because of an immune response to gangliosides such as GM1 [128]. It has also been suggested that this reaction might have been facilitated by contamination with the gangliosides containing the sialic acid Neu5Gc [127]. This, together with the emergence of 'mad cow' disease, terminated such studies. However, the original animal observations remain valid, and the approach might deserve re-visiting in the future.

\section{Pulmonary medicine}

Sialic acids are prominently expressed along the epithelial border lining the airways and are also major components of the secreted mucins in the airways. As mentioned earlier, these represent binding sites for pathogens such as the influenza virus. They also provide the negative charge and hydrophilicity that contribute to the rheological properties of mucus [85], which serves to lubricate the airways, as well as trapping pathogens and other unwanted components of inhaled air. Inappropriate, excessive or abnormal production of mucus can be pathological. An extreme example is cystic fibrosis, a genetic defect in a chloride channel that secondarily results in altered glycosylation of mucins, with decreased sialylation and increased sulfation being prominent [129]. The link between these glycosylation differences and the changes in physical properties of the mucus have not been fully elucidated. In a related matter, the Pseudomonas strain that colonizes the airways in cystic fibrosis can use sialic acids as binding sites [130].

\section{Endocrinology}

Sialic acids are found on circulating glycoprotein hormones such as those originating from the pituitary gland [luteinizing hormone (LH) and follicle-stimulating hormone (FSH)] and from the placenta [human chorionic gonadotropin (hCG)]. While the N-glycans of hCG and FSH are completely sialylated, those of the LH can instead undergo an unusual modification, with addition of 4- $O$-sulfated GalNAc termini [131]. These glycosylation differences determine the fate of LH in circulation, with the sulfated molecules being rapidly cleared by a specific receptor in the liver. This in turn determines circulatory half-life and the sharpness of the spikes of these hormones in the female circulation, which eventually optimize the reproductive cycle [131]. Recent evidence using gene knockout mice has confirmed a key role for these glycan differences in reproductive biology [132]. By contrast, the sialylated hCG originating from the placenta persists in the circulation for much longer, something that is most appropriate for the pregnant state.

\section{Nephrology}

Sialic acids are highly concentrated in the glomerular basement membrane, being displayed on the major glycoprotein of the podocytes of the glomerular basement membrane [13]. The level and distribution of sialic acids affect the efficient filtration functions of the membrane [14]. In so-called 'minimal change' nephrosis, there is a loss of sialic acids in this region, and a similar situation can be induced in animal models with certain drugs. The mechanism of sialic acid loss in the naturally occurring disease remains uncertain. Some cases of hemolyticuremic syndrome have implicated neuraminidases (sialidases) released during bacterial infections [133]. The aberrant sialylation of IgA immunoglobulin seen in IgA nephropathy [134] is likely 
to be explained by the somatic loss of the X-linked Cosmc gene in certain antibody-secreting cells (see discussion above regarding the role of the same gene loss in blood diseases and cancer).

\section{Gastroenterology}

As with the lung and airways, the entire lining of the gastrointestinal tract has a dense and rich array of sialic acids, on both cell surface and secreted molecules. Many of the comments made above concerning the airways apply to the gastrointestional tract as well. The stomach typically has an acidic environment in which sialic acids can be chemically released, and sialic acid content tends to be low, often replaced by sulfation. However, there is sufficient sialic acid remaining for it to be used as one of the receptors for Helicobacter pylori [135], the pathogen that facilitates ulcer disease and gastric cancer. Further down in the intestinal tract it is common to find highly modified sialic acids, in which addition of $O$-acetyl esters is dominant [136]. The reason is not clear, but such modifications do block both the binding of a variety of pathogens and hinder the action of sialidases released by other pathogens. The highest density of these modifications is found in the colon, where one can find di- $O$-acetylated and even tri$O$-acetylated sialic acids. Interestingly, this modification tends to decrease or even disappear in the course of development of both ulcerative colitis and colon carcinoma [137]. The significance of this change is uncertain, but there has been discussion of its use as a biomarker for early cancer.

\section{Hepatology}

The liver secretes a large number of glycoproteins into the circulation, all of which are sialylated on the termini of their glycans. As mentioned earlier, the addition of these sialic acids assures the survival of these serum proteins, and their removal can result in rapid clearance mediated by hepatic receptors that recognize the underlying sugar chain $[20,21]$. This is also of relevance in biotechnology, in that many biotherapeutic agents must be produced as glycoproteins, which require adequate sialic acid capping of their glycans to avoid rapid clearance [22]. More recently, it has been shown that the classic hepatic asialoglycoprotein 'Ashwell receptor' might serve to reduce the level of coagulation determinants, such as platelets and Von Willebrand factor, that have been desialylated by a sialidase released during sepsis with organisms like pneumococcus [138]. Far from being a negative consequence, it appears that this clearance process serves to protect the organism from excessive intravascular coagulation and death [138].

\section{Dermatology}

In inflammatory skin diseases, the infiltration of skin by lymphocytes is mediated via recognition of sialic-acid-containing molecules that act as ligands for the selectins (see above). The subsequent recruitment of innate immune cells into the area of inflammation is also mediated by the selectins [139]. Gangliosides are expressed prominently in melanomas, where sialic acid modifications can generate a relatively tumor-specific antigen called $9-O$-acetylGD3 [140,141].

\section{Conclusions and future prospects}

This brief tour provides some examples of the significance of sialic acids in normal and pathological states, with some emphasis on the most recent advances. Given the ubiquitous yet diverse expression patterns of sialic acids and the limited amount of research done in this area, it is reasonable to suggest that we are only seeing the proverbial 'tip of the iceberg' and that many more functions of sialic acids, together with their roles in physiological and pathological processes, remain to be uncovered (see examples in Box 1). This is certainly a fascinating area 
of cellular and molecular biology in which much work still needs to be done, and it can provide great opportunities for young investigators interested in pursuing new challenges.

\section{Examples of outstanding questions about sialic acids in health and disease}

- Why is there such a high density of sialic acids on the luminal face of endothelial cells?

- Is it possible to better control sialylation levels and eliminate the non-human sialic acid Neu5Gc from biotherapeutic glycoproteins, such as antibodies and cytokines?

- Is it possible to efficiently produce fully sialylated biotherapeutic glycoproteins in plants?

- Does altered sialylation affect fertilization and implantation?

- What is the role of the uterine agglutinin that binds sialic acids?

- Given the production of viable but abnormal mice with several different sialylation defects, are there corresponding human genetic disorders yet to be recognized?

- Is it possible to prevent invasion by sialic-acid-recognizing pathogens by altering cell surface sialylation and/or soluble blocking agents?

- What is the best way to monitor for the dangerous adaptation in binding preference of avian influenza viruses towards human sialylated receptors?

- Are pathogens expressing complex sialylated glycans that mimic human structures taking advantage of inhibitory Siglecs on innate immune cells?

- How do the changes in sialylation that take place during inflammatory acute phase reactions alter the immune response?

- Can clinically approved heparins be used as surrogate agents to block selectinmediated pathologies?

- Can we find an orally active agent that will efficiently block selectins in chronic inflammatory states?

- Are there other diseases caused by Cosmc mutations that allow the overproduction of sialyl-Tn?

- Are forms of sialyl-Tn with modified sialic acids even more tumor-specific?

- Can we take advantage of enhanced Neu5Gc incorporation into tumor cells to find and target new tumor-specific epitopes?

- How exactly are dietary non-human sialic acids metabolized and incorporated into the body?

- Can manipulation of polysialic acid levels be used to enhance neural regeneration after injury?

- Can we modulate glomerular podocyte sialic acid levels to correct nephrotic syndromes?

- Can we alter the action of pathogen-expressed sialidases in favor of the host? 


\section{Acknowledgements}

The author gratefully acknowledges critical comments from Nissi Varki and research support from the National Institutes of Health and the Mathers Foundation. Given the wide scope of this review and the space restrictions, the listed references only represent examples of papers on the cited topics.

\section{References}

1. Crick F. Central dogma of molecular biology. Nature 1970;227:561-563. [PubMed: 4913914]

2. Sharon N, Lis H. Glycoproteins: research booming on long-ignored ubiquitous compounds. Mol. Cell. Biochem 1982;42:167-187. [PubMed: 7062912]

3. Rademacher TW, et al. Glycobiology. Annu. Rev. Biochem 1988;57:785-838. [PubMed: 3052290]

4. Varki, A., et al. Essentials of Glycobiology. 1st edn. Cold Spring Harbor Press; 1999.

5. Drickamer, K.; Taylor, M. Introduction to Glycobiology. 2nd edn. Oxford University Press; 2006.

6. Schauer R. Achievements and challenges of sialic acid research. Glycoconj. J 2000;17:485-499. [PubMed: 11421344]

7. Angata T, Varki A. Chemical diversity in the sialic acids and related $\alpha$-keto acids: an evolutionary perspective. Chem. Rev 2002;102:439-469. [PubMed: 11841250]

8. Varki A. Glycan-based interactions involving vertebrate sialic-acid-recognizing proteins. Nature 2007;446:1023-1029. [PubMed: 17460663]

9. Ilver D, et al. Bacterium-host protein-carbohydrate interactions. Methods Enzymol 2003;363:134157. [PubMed: 14579573]

10. Lehmann F, et al. Sialic acid-specific lectins: occurrence, specificity and function. Cell. Mol. Life Sci 2006;63:1331-1354. [PubMed: 16596337]

11. Vimr ER, et al. Diversity of microbial sialic acid metabolism. Microbiol. Mol. Biol. Rev 2004;68:132153. [PubMed: 15007099]

12. Varki A, Angata T. Siglecs - the major subfamily of I-type lectins. Glycobiology 2006;16:1R-27R. [PubMed: 16118287]

13. Dekan G, et al. Sulfate contributes to the negative charge of podocalyxin, the major sialoglycoprotein of the glomerular filtration slits. Proc. Natl. Acad. Sci. U. S. A 1991;88:5398-5402. [PubMed: 2052617]

14. Gelberg $\mathrm{H}$, et al. In vivo enzymatic removal of $\alpha 2-6$-linked sialic acid from the glomerular filtration barrier results in podocyte charge alteration and glomerular injury. Lab. Invest 1996;74:907-920. [PubMed: 8642786]

15. Weinhold B, et al. Genetic ablation of polysialic acid causes severe neurodevelopmental defects rescued by deletion of the neural cell adhesion molecule. J. Biol Chem 2005;280:42971-42977. [PubMed: 16267048]

16. Johnson CP, et al. Direct evidence that neural cell adhesion molecule (NCAM) polysialylation increases intermembrane repulsion and abrogates adhesion. J. Biol. Chem 2005;280:137-145. [PubMed: 15504723]

17. El Maarouf A, et al. Use of polysialic acid in repair of the central nervous system. Proc. Natl. Acad. Sci. U. S. A 2006;103:16989-16994. [PubMed: 17075041]

18. Rutishauser U. Polysialic acid in the plasticity of the developing and adult vertebrate nervous system. Nat. Rev. Neurosci 2008;9:26-35. [PubMed: 18059411]

19. Born GV, Palinski W. Unusually high concentrations of sialic acids on the surface of vascular endothelia. Br. J. Exp. Pathol 1985;66:543-549. [PubMed: 4063159]

20. Ashwell G, Harford J. Carbohydrate-specific receptors of the liver. Annu. Rev. Biochem 1982;51:531-554. [PubMed: 6287920]

21. Weigel PH, Yik JH. Glycans as endocytosis signals: the cases of the asialoglycoprotein and hyaluronan/chondroitin sulfate receptors. Biochim. Biophys. Acta 2002;1572:341-363. [PubMed: 12223279]

22. Raju TS, et al. Glycoengineering of therapeutic glycoproteins: In vitro galactosylation and sialylation of glycoproteins with terminal $\mathrm{N}$-acetylglucosamine and galactose residues. Biochemistry 2001;40:8868-8876. [PubMed: 11467948] 
23. Bork K, et al. Enhanced sialylation of EPO by overexpression of UDP-GlcNAc 2-epimerase/ManAc kinase containing a sialuria mutation in CHO cells. FEBS Lett 2007;581:4195-4198. [PubMed: 17706199]

24. Hamilton SR, Gerngross TU. Glycosylation engineering in yeast: the advent of fully humanized yeast. Curr. Opin. Biotechnol 2007;18:387-392. [PubMed: 17951046]

25. Betenbaugh MJ, et al. Biosynthesis of human-type N-glycans in heterologous systems. Curr. Opin. Struct. Biol 2004;14:601-606. [PubMed: 15465322]

26. Miwa Y, et al. Are N-glycolylneuraminic acid (Hanganutziu-Deicher) antigens important in pig-tohuman xenotransplantation? Xenotransplantation 2004;11:247-253. [PubMed: 15099204]

27. Martin MJ, et al. Human embryonic stem cells express an immunogenic nonhuman sialic acid. Nat. Med 2005;11:228-232. [PubMed: 15685172]

28. Hashii N, et al. Study on the quality control of cell therapy products. Determination of Nglycolylneuraminic acid incorporated into human cells by nano-flow liquid chromatography/Fourier transformation ion cyclotron mass spectrometry. J. Chromatogr. A 2007;1160:263-269. [PubMed: 17570377]

29. Heiskanen A, et al. N-glycolylneuraminic acid xenoantigen contamination of human embryonic and mesenchymal stem cells is substantially reversible. Stem Cells 2007;25:197-202. [PubMed: 17008421]

30. Qian J, et al. Structural characterization of N-linked oligosaccharides on monoclonal antibody cetuximab by the combination of orthogonal matrix-assisted laser desorption/ionization hybrid quadrupole-quadrupole time-of-flight tandem mass spectrometry and sequential enzymatic digestion. Anal. Biochem 2007;364:8-18. [PubMed: 17362871]

31. Bardor M, et al. Mechanism of uptake and incorporation of the non-human sialic acid Nglycolylneuraminic acid into human cells. J. Biol. Chem 2005;280:4228-4237. [PubMed: 15557321]

32. Noguchi A, et al. Failure of human immunoresponse to N-glycolylneuraminic acid epitope contained in recombinant human erythropoietin. Nephron 1996;72:599-603. [PubMed: 8730428]

33. Zhu A, Hurst R. Anti-N-glycolylneuraminic acid antibodies identified in healthy human serum. Xenotransplantation 2002;9:376-381. [PubMed: 12371933]

34. Tangvoranuntakul $P$, et al. Human uptake and incorporation of an immunogenic nonhuman dietary sialic acid. Proc. Natl. Acad. Sci. U. S. A 2003;100:12045-12050. [PubMed: 14523234]

35. Nguyen DH, et al. Effects of natural human antibodies against a nonhuman sialic acid that metabolically incorporates into activated and malignant immune cells. J. Immunol 2005;175:228236. [PubMed: 15972653]

36. Hokke $\mathrm{CH}$, et al. Sialylated carbohydrate chains of recombinant human glycoproteins expressed in Chinese hamster ovary cells contain traces of N-glycolylneuraminic acid. FEBS Lett 1990;275:914. [PubMed: 2124546]

37. Bergwerff AA, et al. Variation in N-linked carbohydrate chains in different batches of two chimeric monoclonal IgG1 antibodies produced by different murine SP2/0 transfectoma cell subclones. Glycoconj. J 1995;12:318-330. [PubMed: 7496147]

38. Bloom JW, et al. Cell line and site specific comparative analysis of the $\mathrm{N}$-linked oligosaccharides on human ICAM/-1des454-532 by electrospray ionization mass spectrometry. Biochemistry 1996;35:1856-1864. [PubMed: 8639667]

39. Baker KN, et al. Metabolic control of recombinant protein N-glycan processing in NSO and CHO cells. Biotechnol. Bioeng 2001;73:188-202. [PubMed: 11257601]

40. Zhou Q, et al. Effect of genetic background on glycosylation heterogeneity in human antithrombin produced in the mammary gland of transgenic goats. J. Biotechnol 2005;117:57-72. [PubMed: 15831248]

41. Ludwig TE, et al. Derivation of human embryonic stem cells in defined conditions. Nat. Biotechnol 2006;24:185-187. [PubMed: 16388305]

42. Benatuil L, et al. The influence of natural antibody specificity on antigen immunogenicity. Eur. J. Immunol 2005;35:2638-2647. [PubMed: 16082726]

43. Mengerink KJ, Vacquier VD. Glycobiology of sperm-egg interactions in deuterostomes. Glycobiology 2001;11:37R-43R. [PubMed: 11181560] 
44. DeSouza MM, et al. Mucin functions and expression in mammalian reproductive tract tissues. Biochem. Biophys. Res. Commun 1998;247:1-6. [PubMed: 9636643]

45. Chatterji $U$, et al. Paracrine effects of a uterine agglutinin are mediated via the sialic acids present in the rat uterine endometrium. Mol. Cell. Biochem 2000;215:47-55. [PubMed: 11204455]

46. Velasquez JG, et al. Role of sialic acid in bovine sperm-zona pellucida binding. Mol. Reprod. Dev 2007;74:617-628. [PubMed: 17044044]

47. Schwarzkopf M, et al. Sialylation is essential for early development in mice. Proc. Natl. Acad. Sci. U. S. A 2002;99:5267-5270. [PubMed: 11929971]

48. Altheide TK, et al. System-wide genomic and biochemical comparisons of sialic acid biology among primates and rodents: evidence for two modes of rapid evolution. J. Biol. Chem 2006;281:2568925702. [PubMed: 16769723]

49. Arai A, et al. A novel mutation in the GNE gene and a linkage disequilibrium in Japanese pedigrees. Ann. Neurol 2002;52:516-519. [PubMed: 12325084]

50. Huizing M, et al. Hypoglycosylation of $\alpha$-dystroglycan in patients with hereditary IBM due to GNE mutations. Mol. Genet. Metab 2004;81:196-202. [PubMed: 14972325]

51. Martin PT, Freeze HH. Glycobiology of neuromuscular disorders. Glycobiology 2003;13:67R-75R.

52. Penner J, et al. Influence of UDP-GlcNAc 2-epimerase/ManNAc kinase mutant proteins on hereditary inclusion body myopathy. Biochemistry 2006;45:2968-2977. [PubMed: 16503651]

53. Galeano B, et al. Mutation in the key enzyme of sialic acid biosynthesis causes severe glomerular proteinuria and is rescued by N-acetylmannosamine. J. Clin. Invest 2007;117:1585-1594. [PubMed: 17549255]

54. Malicdan MC, et al. A Gne knockout mouse expressing human GNE D176V mutation develops features similar to distal myopathy with rimmed vacuoles or hereditary inclusion body myopathy. Hum. Mol. Genet 2007;16:2669-2682. [PubMed: 17704511]

55. Weiss P, et al. Identification of the metabolic defect in sialuria. J. Biol. Chem 1989;264:17635-17636. [PubMed: 2808337]

56. Leroy JG, et al. Dominant inheritance of sialuria, an inborn error of feedback inhibition. Am. J. Hum. Genet 2001;68:1419-1427. [PubMed: 11326336]

57. Enns GM, et al. Clinical course and biochemistry of sialuria. J. Inherit. Metab. Dis 2001;24:328-336. [PubMed: 11486897]

58. Verheijen FW, et al. A new gene, encoding an anion transporter, is mutated in sialic acid storage diseases. Nat. Genet 1999;23:462-465. [PubMed: 10581036]

59. Kleta R, et al. Biochemical and molecular analyses of infantile free sialic acid storage disease in North American children. Am. J. Med. Genet. A 2003;120A:28-33. [PubMed: 12794688]

60. Biancheri R, et al. An Italian severe Salla disease variant associated with a SLC17A5 mutation earlier described in infantile sialic acid storage disease. Clin. Genet 2002;61:443-447. [PubMed: 12121352]

61. Seyrantepe V, et al. Molecular pathology of NEU1 gene in sialidosis. Hum. Mutat 2003;22:343-352. [PubMed: 14517945]

62. Martin LT, et al. Genetically altered mice with different sialyltransferase deficiencies show tissuespecific alterations in sialylation and sialic acid 9-O-acetylation. J. Biol Chem 2002;277:3293032938. [PubMed: 12068010]

63. Wearne KA, et al. Use of lectins for probing differentiated human embryonic stem cells for carbohydrates. Glycobiology 2006;16:981-990. [PubMed: 16809438]

64. Pickup JC, et al. Serum sialic acid concentration and coronary heart disease in NIDDM. Diabetes Care 1995;18:1100-1103. [PubMed: 7587844]

65. Crook MA, et al. Serum sialic acid, a risk factor for cardiovascular disease, is increased in IDDM patients with microalbuminuria and clinical proteinuria. Diabetes Care 1994;17:305-310. [PubMed: 8026286]

66. Pönniö M, et al. Serum sialic acid in a random sample of the general population. Clin. Chem 1999;45:1842-1849. [PubMed: 10508132]

67. Afzali B, et al. Raised plasma total sialic acid levels are markers of cardiovascular disease in renal dialysis patients. J. Nephrol 2003;16:540-545. [PubMed: 14696756] 
68. Jamieson JC, et al. Sialyltransferase: a novel acute-phase reactant. Comp. Biochem. Physiol. B 1993;105:29-33. [PubMed: 7684961]

69. Appenheimer MM, et al. Biologic contribution of P1 promoter-mediated expression of ST6Gal I sialyltransferase. Glycobiology 2003;13:591-600. [PubMed: 12672700]

70. Yasukawa Z, et al. Inflammation-dependent changes in $\alpha 2,3-, \alpha 2,6-$, and $\alpha 2,8$-sialic acid glycotopes on serum glycoproteins in mice. Glycobiology 2005;15:827-837. [PubMed: 15858074]

71. Gunnarsson P, et al. The acute-phase protein alpha 1-acid glycoprotein (AGP) induces rises in cytosolic $\mathrm{Ca}^{2+}$ in neutrophil granulocytes via sialic acid binding immunoglobulin-like lectins (siglecs). FASEB J 2007;21:4059-4069. [PubMed: 17675532]

72. Millar JS. The sialylation of plasma lipoproteins. Atherosclerosis 2001;154:1-13. [PubMed: 11137077]

73. Tertov VV, et al. Human plasma transsialidase causes atherogenic modification of low density lipoprotein. Atherosclerosis 2001;159:103-115. [PubMed: 11689212]

74. Romppanen J, et al. Serum sialic acid as a marker of alcohol consumption: effect of liver disease and heavy drinking. Alcohol. Clin. Exp. Res 2002;26:1234-1238. [PubMed: 12198399]

75. Yamashita K, et al. Sugar chains of serum transferrin from patients with carbohydrate deficient glycoprotein syndrome. Evidence of asparagine-N-linked oligosaccharide transfer deficiency. J. Biol. Chem 1993;268:5783-5789. [PubMed: 8449944]

76. Jaeken J, Carchon H. The carbohydrate-deficient glycoprotein syndromes: an overview. J. Inherit. Metab. Dis 1993;16:813-820. [PubMed: 8295395]

77. Freeze HH, Aebi M. Altered glycan structures: the molecular basis of congenital disorders of glycosylation. Curr. Opin. Struct. Biol 2005;15:490-498. [PubMed: 16154350]

78. Suzuki Y. Sialobiology of influenza: molecular mechanism of host range variation of influenza viruses. Biol. Pharm. Bull 2005;28:399-408. [PubMed: 15744059]

79. Russell CJ, Webster RG. The genesis of a pandemic influenza virus. Cell 2005;123:368-371. [PubMed: 16269328]

80. Shinya K, et al. Avian flu: influenza virus receptors in the human airway. Nature 2006;440:435-436. [PubMed: 16554799]

81. Stevens J, et al. Glycan microarray analysis of the hemagglutinins from modern and pandemic influenza viruses reveals different receptor specificities. J. Mol. Biol 2006;355:1143-1155. [PubMed: 16343533]

82. Gagneux P, et al. Human-specific regulation of $\alpha 2-6$ linked sialic acids. J. Biol. Chem 2003;278:48245-48250. [PubMed: 14500706]

83. Glaser L, et al. A single amino acid substitution in 1918 influenza virus hemagglutinin changes receptor binding specificity. J. Virol 2005;79:11533-11536. [PubMed: 16103207]

84. Stevens J, et al. Structure and receptor specificity of the hemagglutinin from an H5N1 influenza virus. Science 2006;312:404-410. [PubMed: 16543414]

85. Rose MC, Voynow JA. Respiratory tract mucin genes and mucin glycoproteins in health and disease. Physiol. Rev 2006;86:245-278. [PubMed: 16371599]

86. Charland N, et al. Role of capsular sialic acid in virulence and resistance to phagocytosis of Streptococcus suis capsular type 2. FEMS Immunol. Med. Microbiol 1996;14:195-203. [PubMed: 8856318]

87. Ngampasutadol J, et al. Human factor H interacts selectively with Neisseria gonorrhoeae and results in species-specific complement evasion. J. Immunol 2008;180:3426-3435. [PubMed: 18292569]

88. Madico G, et al. Factor $\mathrm{H}$ binding and function in sialylated pathogenic neisseriae is influenced by gonococcal, but not meningococcal, porin. J. Immunol 2007;178:4489-4497. [PubMed: 17372007]

89. Carlin AF, et al. Group B streptococcal capsular sialic acids interact with siglecs (immunoglobulinlike lectins) on human leukocytes. J. Bacteriol 2007;189:1231-1237. [PubMed: 16997964]

90. Crocker PR, et al. Siglecs and their roles in the immune system. Nat. Rev. Immunol 2007;7:255-266. [PubMed: 17380156]

91. Van Dyken SJ, et al. Structural and mechanistic features of protein O-glycosylation linked to CD8 ${ }^{+}$ T cell apoptosis. Mol. Cell Biol 2007;27:1096-1111. [PubMed: 17101770] 
92. Wuensch SA, et al. Murine B cell differentiation is accompanied by programmed expression of multiple novel beta-galactoside $\alpha 2,6$-sialyltransferase mRNA forms. Glycobiology 2000;10:67-75. [PubMed: 10570225]

93. Oetke C, et al. Sialoadhesin-deficient mice exhibit subtle changes in B- and T-cell populations and reduced immunoglobulin m levels. Mol. Cell. Biol 2006;26:1549-1557. [PubMed: 16449664]

94. Liang F, et al. Monocyte differentiation up-regulates the expression of the lysosomal sialidase, Neu1, and triggers its targeting to the plasma membrane via major histocompatibility complex class IIpositive compartments. J. Biol. Chem 2006;281:27526-27538. [PubMed: 16835219]

95. Nan X, et al. Sialidase expression in activated human T lymphocytes influences production of IFN$\gamma$. J. Leukoc. Biol 2007;81:284-296. [PubMed: 17028199]

96. Rosen SD. Ligands for L-selectin: homing, inflammation, and beyond. Annu. Rev. Immunol 2004;22:129-156. [PubMed: 15032576]

97. Ley K. The role of selectins in inflammation and disease. Trends Mol. Med 2003;9:263-268. [PubMed: 12829015]

98. Dong ZM, et al. Combined role of P- and E-selectins in atherosclerosis. J. Clin. Invest 1998;102:145152. [PubMed: 9649568]

99. Jilma B, et al. The single nucleotide polymorphism Ser128Arg in the E-selectin gene is associated with enhanced coagulation during human endotoxemia. Blood 2005;105:2380-2383. [PubMed: 15546947]

100. Tregouet DA, et al. Specific haplotypes of the P-selectin gene are associated with myocardial infarction. Hum. Mol. Genet 2002;11:2015-2023. [PubMed: 12165563]

101. Gallart T, et al. Anti-Sia-Ib (anti-Gd) cold agglutinins bind the domain NeuNAca2-3Gal in sialyl Lewisx, sialyl Lewisa, and related carbohydrates on nucleated cells and in soluble cancer-associated mucins. Blood 1997;90:1576-1587. [PubMed: 9269776]

102. Kewitz S, et al. Anti-Pr cold agglutinins recognize immunodominant $\alpha 2,3$ - or $\alpha 2,6$-sialyl groups on glycophorins. Glycoconj. J 1995;12:714-720. [PubMed: 8595264]

103. Feizi T, Loveless RW. Carbohydrate recognition by Mycoplasma pneumoniae and pathologic consequences. Am. J. Respir. Crit. Care Med 1996;154:S133-S136. [PubMed: 8876531]

104. Kim YJ, Varki A. Perspectives on the significance of altered glycosylation of glycoproteins in cancer. Glycoconj. J 1997;14:569-576. [PubMed: 9298689]

105. Chen S, Fukuda M. Cell type-specific roles of carbohydrates in tumor metastasis. Methods Enzymol 2006;416:371-380. [PubMed: 17113879]

106. Varki NM, Varki A. Heparin inhibition of selectin-mediated interactions during the hematogenous phase of carcinoma metastasis: rationale for clinical studies in humans. Semin. Thromb. Hemost 2002;28:53-66. [PubMed: 11885026]

107. Stevenson JL, et al. Heparin attenuates metastasis mainly due to inhibition of P- and L-selectin, but non-anticoagulant heparins can have additional effects. Thromb. Res 2007;120:S107-S111. [PubMed: 18023703]

108. Ajona D, et al. Expression of complement factor $\mathrm{H}$ by lung cancer cells: effects on the activation of the alternative pathway of complement. Cancer Res 2004;64:6310-6318. [PubMed: 15342420]

109. Rhodes JM. Usefulness of novel tumour markers. Ann. Oncol 1999;10:118-121. [PubMed: 10436801]

110. Yin BWT, Lloyd KO. Molecular cloning of the CA125 ovarian cancer antigen - identification as a new mucin, MUC16. J. Biol. Chem 2001;276:27371-27375. [PubMed: 11369781]

111. Wahrenbrock MG, Varki A. Multiple hepatic receptors cooperate to eliminate secretory mucins aberrantly entering the bloodstream: are circulating cancer mucins the 'tip of the iceberg'? Cancer Res 2006;66:2433-2441. [PubMed: 16489050]

112. Wahrenbrock M, et al. Selectin-mucin interactions as a probable molecular explanation for the association of Trousseau syndrome with mucinous adenocarcinomas. J. Clin. Invest 2003;112:853862. [PubMed: 12975470]

113. Varki A. Trousseau's syndrome: multiple definitions and multiple mechanisms. Blood 2007;110:1723-1729. [PubMed: 17496204] 
114. Malykh YN, et al. N-glycolylneuraminic acid in human tumours. Biochimie 2001;83:623-634. [PubMed: 11522391]

115. Yin J, et al. Hypoxic culture induces expression of sialin, a sialic acid transporter, and cancerassociated gangliosides containing non-human sialic acid on human cancer cells. Cancer Res 2006;66:2937-2945. [PubMed: 16540641]

116. Ju T, Cummings RD. Protein glycosylation: chaperone mutation in Tn syndrome. Nature 2005;437:1252. [PubMed: 16251947]

117. Ju T, et al. Human tumor antigens Tn and sialyl Tn arise from mutations in Cosmc. Cancer Res 2008;68:1636-1646. [PubMed: 18339842]

118. Schnaar RL. Glycolipid-mediated cell-cell recognition in inflammation and nerve regeneration. Arch. Biochem. Biophys 2004;426:163-172. [PubMed: 15158667]

119. Pan B, et al. Myelin-associated glycoprotein and complementary axonal ligands, gangliosides, mediate axon stability in the CNS and PNS: neuropathology and behavioral deficits in single- and double-null mice. Exp. Neurol 2005;195:208-217. [PubMed: 15953602]

120. Yang LJ, et al. Sialidase enhances spinal axon outgrowth in vivo. Proc. Natl. Acad. Sci. U. S. A 2006;103:11057-11062. [PubMed: 16847268]

121. Simpson MA, et al. Infantile-onset symptomatic epilepsy syndrome caused by a homozygous lossof-function mutation of GM3 synthase. Nat. Genet 2004;36:1225-1229. [PubMed: 15502825]

122. Yamashita T, et al. Enhanced insulin sensitivity in mice lacking ganglioside GM3. Proc. Natl. Acad. Sci. U. S. A 2003;100:3445-3449. [PubMed: 12629211]

123. Yuki N. Carbohydrate mimicry: a new paradigm of autoimmune diseases. Curr. Opin. Immunol 2005;17:577-582. [PubMed: 16229995]

124. Hughes RA, Cornblath DR. Guillain-Barré syndrome. Lancet 2005;366:1653-1666. [PubMed: 16271648]

125. Chai Q, et al. Structural basis of cell surface receptor recognition by botulinum neurotoxin B. Nature 2006;444:1096-1100. [PubMed: 17167418]

126. Candelise L, Ciccone A. Gangliosides for acute ischemic stroke. Stroke 2002;33:2336. [PubMed: 12215609]

127. Odaka M, et al. Antibodies to GM1(NeuGc) in Guillain-Barré syndrome after ganglioside therapy. J. Neurol. Sci 2000;175:96-106. [PubMed: 10831769]

128. Yuki N, et al. Carbohydrate mimicry between human ganglioside GM1 and Campylobacter jejuni lipooligosaccharide causes Guillain-Barré syndrome. Proc. Natl. Acad. Sci. U. S. A 2004;101:11404-11409. [PubMed: 15277677]

129. Rhim AD, et al. Terminal glycosylation in cystic fibrosis (CF): a review emphasizing the airway epithelial cell. Glycoconj. J 2001;18:649-659. [PubMed: 12386452]

130. Xia B, et al. Pseudomonas aeruginosa mucoid strain 8830 binds glycans containing the sialyl-Lewis x epitope. Glycoconj. J 2007;24:87-95. [PubMed: 17139557]

131. Roseman DS, Baenziger JU. The Man/GalNAc-4-SO4-receptor: relating specificity to function. Methods Enzymol 2003;363:121-133. [PubMed: 14579572]

132. Mi Y, et al. Ablation of GalNAc-4-sulfotransferase-1 enhances reproduction by altering the carbohydrate structures of luteinizing hormone in mice. J. Clin. Invest 2008;118:1815-1824. [PubMed: 18431515]

133. Erickson LC, et al. Streptococcus pneumoniae-induced hemolytic uremic syndrome: a case for early diagnosis. Pediatr. Nephrol 1994;8:211-213. [PubMed: 8018501]

134. Suzuki H, et al. IgA1-secreting cell lines from patients with IgA nephropathy produce aberrantly glycosylated IgA1. J. Clin. Invest 2008;118:629-639. [PubMed: 18172551]

135. Aspholm M, et al. SabA is the H. pylori hemagglutinin and is polymorphic in binding to sialylated glycans. PLoS Pathog 2006;2:e110. [PubMed: 17121461]

136. Shen Y, et al. O-Acetylation and de-O-acetylation of sialic acids in human colorectal carcinoma. Eur. J. Biochem 2004;271:281-290. [PubMed: 14717696]

137. Corfield AP, et al. Reduction of sialic acid O-acetylation in human colonic mucins in the adenomacarcinoma sequence. Glycoconj. J 1999;16:307-317. [PubMed: 10579699] 
138. Grewal PK, et al. The Ashwell receptor mitigates the lethal coagulopathy of sepsis. Nat. Med 2008;14:648-655. [PubMed: 18488037]

139. Dimitroff CJ, et al. Glycosylation-dependent inhibition of cutaneous lymphocyte-associated antigen expression: implications in modulating lymphocyte migration to skin. Blood 2003;101:602-610. [PubMed: 12393521]

140. Cheresh DA, et al. O-Acetylation of disialoganglioside GD3 by human melanoma cells creates a unique antigenic determinant. Science 1984;225:844-846. [PubMed: 6206564]

141. Kohla G, et al. Gangliosides with O-acetylated sialic acids in tumors of neuroectodermal origin. Neurochem. Res 2002;27:583-592. [PubMed: 12374193] 


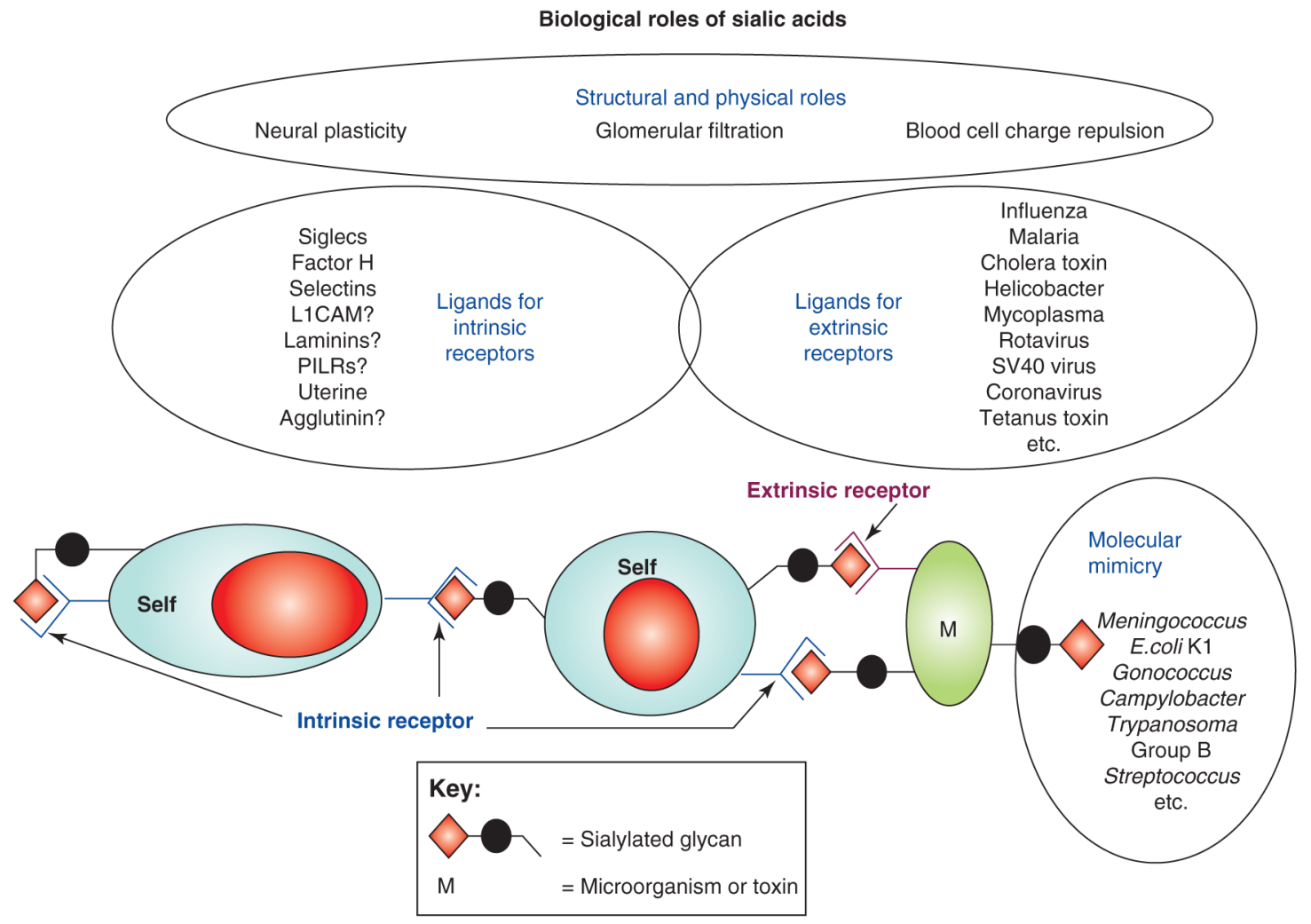

Figure 1.

Some biological and pathological roles of sialic acids. First, due to their negative charge and hydrophilicity, sialic acids have many structural or physical roles, for example in neural plasticity, glomerular filtration or blood cell charge repulsion. Second, sialic acids serve as components of binding sites for various pathogens and toxins $[6,7,9,10]$, such as those listed in Table 1. In most such interactions, a pathogen-binding protein (extrinsic receptor) recognizes certain forms of sialic acids presented in specific linkages to a defined underlying sugar chain. In the case of recognition by extrinsic receptors (pathogen-binding proteins and toxins), only a few examples are listed. Third, sialic acids serve as ligands for intrinsic receptors such as Siglecs and factor $\mathrm{H}[8,10,12,90,96,97]$. The possible interactions between sialic acids (as sialylated glycan molecules) expressed on host cells (self) with intrinsic receptors expressed on the same or different host cells is shown. A final class of functions is 'molecular mimicry', in which successful microbial pathogens decorate themselves with sialic acids, assisting in evasion of host immunity [11] (Table 2). These varied functions of sialic acids are to some extent antagonistic, generating an evolutionary arms race in which vertebrate hosts need to maintain sialic acids for critical endogenous functions - even while constantly changing them to avoid rapidly evolving pathogens that are either binding to or mimicking them [12]. Abbreviations: L1CAM, L1 cell adhesion molecule; PILR, paired immunoglobulin-like receptor. 
Table 1

Examples of pathogens that bind to sialic acids on human cell surfaces

\begin{tabular}{|c|c|c|}
\hline Pathogen & Binding protein & Known target sialylated sequence \\
\hline Human Influenza A & Hemagglutinin & Sia $\alpha 2-6 \mathrm{Gal}(\mathrm{NAc})$ \\
\hline Avian Influenza A & Hemagglutinin & Sia $\alpha 2-3 \mathrm{Gal} \beta 1-$ \\
\hline Human Influenza $\mathrm{C}$ & Hemagglutinin-esterase & 9-O-Ac-Sia $2-$ \\
\hline Vibrio cholerae & Toxin & Gal $\beta 1-3$ GalNAc $\beta 1,4($ Sia $\alpha 2-3)$ Lac-Cer \\
\hline Plasmodium falciparum & EBA-175 & Sia $\alpha 2-3 \mathrm{Gal} \beta 1-3(\mathrm{Sia} \alpha 2-6)$ GalNAc-O- \\
\hline Clostridium botulinum & Toxin & Polysialogangliosides \\
\hline Helicobacter pylori & SabA & Sia 2 -3Gal on gangliosides \\
\hline
\end{tabular}


Table 2

Pathogen

Examples of pathogens that express sialic acids on their surfaces

Sialic acid synthesized by pathogen

Neisseria meningitidis B

Escherichia coli $\mathrm{K} 1$

Group B Streptococcus

Campylobacter jejuni

Host sialic acid taken up by pathogen

Hemophilus influenzae

Hemophilus ducreyi

Meningitis

Neonatal meningitis

Neonate and infant infections

Host sialic acid transferred by trans-sialidase

Trypanosoma cruzi $\quad$ Chagas disease

Corynebacterium diphtheriae Diphtheria

Neisseria

$\begin{array}{ll}\text { Neisseria gonorrhoea } & \text { Gonorrhoea } \\ \text { Neisseria meningitidis group A } & \text { Meningitis }\end{array}$

Source of sialic acid un known

Sporotrichium schenkii

Skin infection

Aspergillus fumigatus

Opportunistic infections 


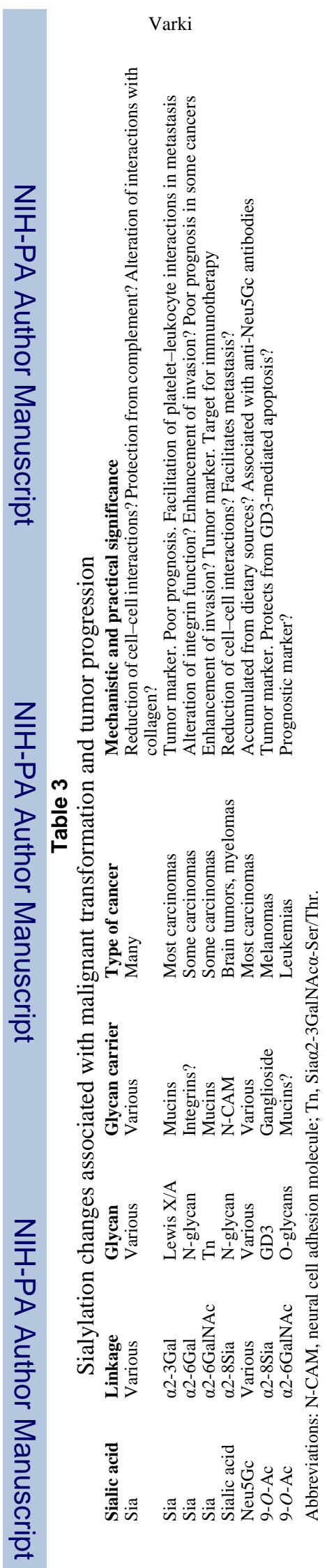

Page 20

Trends Mol Med. Author manuscript; available in PMC 2009 August 1. 